\title{
AS POTENCIALIDADES DE PROCESSOS DE AUTORIA COLABORATIVA NA FORMAÇÃO ESCOLAR DOS INDIVÍDUOS: APROFUNDANDO UMA FACETA DO CONCEITO DE INCLUSÃO DIGITAL
}

Acadêmica: Andressa Foresti, Universidade de Passo Fundo, 9610@1ci.upf.br

Prof $^{\text {.: }}$ Dr. Adriano Canabarro Teixeira, Universidade de Passo Fundo, teixeira@upf.br

\section{POTENTIALS OF THE COLLABORATIVE AUTHORSHIP IN SCHOLAR FORMATION OF THE INDIVIDUAL: DEEPENING A FACET OF DIGITAL INCLUSION IDEA}

\begin{abstract}
This article has as main purpose to analyse a proposal of the collaborative authorship with a digital inclusion basic idea. To accomplish this purpose, a literature revision was made, realizing dialogue with different authors. Besides this purpose, deepen the digital inclusion and collaborative authorship idea. To validity those ideas, search and evaluation a collaborative authorship environment, besides the experience accomplishment. Finally, a verification of the obtained results in the experience proposed comparing with ideas already known was made.
\end{abstract}

Keywords: Digital inclusion, collaborative authorship, educative computer science.

Resumo: Este trabalho tem como principal objetivo analisar uma proposta de autoria colaborativa com base no conceito de inclusão digital. Para que esse objetivo fosse alcançado, foi feita uma revisão da literatura, realizando diálogos com diversos autores. Além desse objetivo, aprofundaram-se os conceitos de inclusão digital e autoria colaborativa. Para a validação desses conceitos, pesquisou-se e avaliouse um ambiente de autoria colaborativa, além da realização da experiência. Para finalizar, foi feita uma verificação dos resultados obtidos na experiência proposta comparando-os com os conceitos já conhecidos.

Palavras-chaves: Inclusão digital, autoria colaborativa, informática educativa. 


\title{
1. Introdução
}

O presente trabalho tem por finalidade abordar uma das facetas da inclusão digital, a autoria colaborativa. Neste sentido, na revisão da literatura, diversos autores de várias áreas foram usados para sua sustentação e para possibilitar o entendimento da dinâmica social contemporânea.

Para tanto, propôs-se a contraposição do modelo de ensino tradicional, entendido como um processo vertical e hierarquizado, com o de autoria colaborativa, tendo como principal objetivo verificar de que forma as tecnologias de rede contribuem para a formação escolar do indivíduo.

Para que essa comparação fosse possível, foi utilizado um ambiente virtual de aprendizagem, ColaborE ${ }^{1}$, que desse sustentação e que potencializasse processos de autoria colaborativa a partir da apropriação pelas tecnologias de rede.

Com isso, alguns objetivos específicos foram definidos, como: refletir sobre a necessária ampliação teórico-conceitual do conceito de inclusão digital e de autoria colaborativa na dinâmica social contemporânea. Também se fez necessária uma atividade de pesquisa e avaliação de um ambiente de autoria colaborativa.

Como parte do processo de localização contextual do trabalho, foi feita uma breve análise da sociedade contemporânea a partir dos conceitos de cibercultura e hipertexto. Após essa revisão da literatura, expõe-se a metodologia utilizada e, por fim, as considerações finais.

\section{Análise da Sociedade Contemporânea}

Atualmente, a sociedade tem vivenciado uma nova perspectiva intimamente ligada à tecnologia, onde o ciberespaço, formando as redes técnica e social, institui inúmeras formas de sociabilidade on-line pelas quais as pessoas podem, entre outras coisas, se comunicar.

\begin{abstract}
Segundo Lévy, o ciberespaço é uma grande rede interconectada mundialmente, com um processo de comunicação, universal, "sem" totalidade. A universalidade sem totalidade segue uma linha interativa de comunicação, possibilitando a todos navegantes da grande "rede" participarem democraticamente num modelo interativo de todos para todos. (LÉVY apud WIKIPEDIA $\left.{ }^{2}, 2006\right)$.
\end{abstract}

Com isso, estamos vivendo uma revolução: a revolução da comunicação via internet. Vivemos em um meio em que é praticamente impossível estarmos desconectados, onde quer que estejamos, a priori, existe a possibilidade de, por meio da rede, nos conectarmos e nos comunicarmos com outras pessoas, submetidas a um processo de conexão generalizada, que é uma das características deste espaço interativo e que são potencializadas pelas tecnologias de rede. (LEMOS, 2003).

\footnotetext{
${ }^{1}$ Esse ambiente encontra-se disponível no endereço: http://inf.upf.br/colabore. Mais informações em http://inf.upf.br/ 55585/portifolio/port.php.

${ }^{2}$ Utilizou-se o Wikipedia como uma das referências por ela ser um dos exemplos de autoria colaborativa, juntamente com o software livre, indo ao encontro de um dos propósitos desse trabalho: analisar processos e manifestações de autoria colaborativa. 
Sendo assim, algumas características da sociedade contemporânea são: a criação de um novo espaço de interação denominado ciberespaço, o potencial comunicacional instalado, as possibilidades de troca de informações, alta disponibilidade e ampliação dos recursos tecnológicos, dentre outras. Tudo isso, potencializado pelas tecnologias de rede.

Com o exposto até o momento, podemos caracterizar cibercultura como "cultura contemporânea modificada pelas tecnologias de rede, pela sociabilidade on-line, pela navegação planetária pela informação". (LEMOS, 2004a).

Desta forma, na cibercultura é primordial que os indivíduos assumam o papel de nó de rede, postura fundamental da sociedade contemporânea, onde, por meio das tecnologias digitais, seja possível adquirir e ampliar o conhecimento, bem como conectar um nó a outro. Para melhor entender esta dinâmica, é fundamental que se defina o que é uma rede.

\subsection{A lógica das redes}

Ao conceituar rede, Capra afirma que "é um padrão específico de relações entre os processos" (2002, p. 85), isto é, a rede faz parte de um padrão de organização, ou seja, é como se ela fosse uma célula composta por processos, forma e matéria, onde deve haver uma integração entre esses componentes.

Seguindo estas considerações, ainda apoiadas no conceito de Capra, podemos identificar uma das características essenciais da dinâmica das redes, a geração de outras estruturas, que nos permitem interagir e reproduzir ao mesmo tempo. Assim, um nó pode se transformar ou ser substituído por um terceiro nó, contribuindo para a formação de outros nós.

O segundo conceito importante para este entendimento é o de hipertexto, intimamente relacionado a uma estrutura reticular. Ramal coloca que o hipertexto é a "apresentação de informações através de uma rede de nós interconectados por links que pode ser navegada livremente pelo leitor de um modo não-linear”. (2002, p. 87).

Com base nesses conceitos, podemos aprofundar o entendimento a partir dos seis princípios do hipertexto proposto por Lévy (1993) bem como relacioná-lo com as três leis da cibercultura, propostas por Lemos (2003).

A partir destes conceitos é possível realizar a seguinte reflexão: A primeira lei da cibercultura fala sobre a reconfiguração, podendo relacioná-la com três princípios do hipertexto, a saber, que: o primeiro princípio, da metamorfose, diz que a rede deve ser dinâmica e flexível; o terceiro, da multiplicidade e encaixe de escalas, diz que a rede deve ser indeterminada; já o quarto princípio, o da exterioridade, nos diz que a rede deve ser aberta e que esta tende ao infinito; por fim, temos o sexto princípio, mobilidade dos centros, que se relaciona à primeira lei da cibercultura devido à dinamicidade da rede, ou seja, deve haver uma participação ativa dos nós de rede.

Na segunda lei da cibercultura temos a liberação dos pólos de emissão, onde devemos vivenciar práticas de processos dinâmicos, novos e mutantes. (LEMOS, 2003, p. 22). Com isso, se relaciona com quatro princípios do hipertexto. Um deles é o da heterogeneidade, que aponta para a composição da rede por diferentes nós; o terceiro princípio, da multiplicidade e encaixe de escalas, apontando para os nós que podem ser outras redes; já o quarto princípio, da exterioridade, estabelece que uma rede é aberta, 
dinâmica e flexível no seu formato; por fim, o sexto princípio, da mobilidade da rede, propõe que em uma rede, não há um centro.

Por fim, temos a terceira lei da cibercultura, da conexão generalizada, onde nos é colocado que, com tantas mudanças e transformações, nossa sociedade tende a exigir uma postura diferente dos grupos sociais, onde estes devem se inserir e serem autores no ciberespaço, que é um dos pontos fundamentais do cidadão da sociedade conectada. Podemos relacionar essa última lei com três princípios do hipertexto: multiplicidade e encaixe de escalas, exterioridade e topologia, sendo que este último nos diz que tudo está na rede, ou seja, a rede é o espaço.

Portanto, os hipertextos permitem a construção de processos dinâmicos, onde a rede torna-se flexível, democrática e aberta em seu formato, valorizando seus nós e ampliando a riqueza dos processos de troca.

Com isso, é possível verificar que as leis da cibercultura estão intimamente ligadas com a lógica das redes e com os princípios do hipertexto. Temos assim, uma nova forma de avaliar o mundo em que vivemos, que é um mundo voltado para a tecnologia, globalizado e transnacionalizado, onde há novas formas de aprendizado e interação, isto é, novas formas de manifestações socioculturais.

Desse modo, podemos elencar algumas características dessa lógica de redes: reticularidade, horizontalidade e dinamicidade, onde não há um nó principal, pois todos os nós são importantes e devem estar sempre em movimento comunicacional, fortalecendo a dinâmica social.

\subsection{As Tecnologias de Rede}

Para um bom entendimento das tecnologias de rede, pode ser dito que essas são técnicas e procedimentos, e que nem sempre vêm em benefício do ser humano, mas que em contrapartida, influenciam a cultura do homem quando este se apropria dela e passam a ser também uma ferramenta de cunho intelectual.

Verifica-se que o simples fato de uma tecnologia existir já muda o ambiente em que ela está inserida, fazendo com que ela não seja uma tecnologia neutra. (RAMAL, 2002, p. 78). Também contribui nessa reflexão, Milton Santos (2002), onde a partir da identificação de que as tecnologias têm uma intencionalidade e uma racionalidade, afirma que elas não são neutras.

Pode-se dizer também, que a rede, devido ao seu constante movimento comunicacional, gera novas conexões, e por sua vez, ativa novos nós de rede, numa dinâmica mutante, integrando-se à "inteligência coletiva constituída de uma multiplicidade de vozes, culturas e pensamentos". (RAMAL 2002, p.141).

Com esse pressuposto, vimos que a internet veio para conceber novos meios de comunicação. Portanto, comunicar-se por meio da tecnologia é muito mais que enviar e receber mensagens de um para o outro, é mais que uma transmissão linear: é uma nova maneira de aprender e agir, de construir novos alicerces na forma de comunicação e conhecimento, potencializado pela possibilidade da inteligência coletiva. 


\section{Inteligência Coletiva}

Para entender o que é inteligência coletiva, iremos iniciar com a sua definição. Segundo a percepção de Pierre Lévy, inteligência coletiva "é uma inteligência distribuída por toda parte, incessantemente valorizada, coordenada em tempo real, que resulta em uma mobilização efetiva das competências". (2003, p. 28).

Com a inteligência coletiva, as pessoas interagem entre si, compartilham idéias, artigos, textos, imagens, filmes, músicas, enfim, uma infinidade de informações, "construindo processos coletivos" fundamentais à aprendizagem (LEMOS, 2004b) e adquirindo capacidade de criação e desenvolvimento.

Dessa forma, a inteligência coletiva, através do potencial das tecnologias de rede, está se tornando uma importante manifestação de aprendizagem interativa, onde um ajuda o outro e a cada instante mais informações são injetadas na rede, que pode ser potencializada a partir das comunidades virtuais de aprendizagem.

\section{As Comunidades Virtuais de Aprendizagem}

As comunidades virtuais de aprendizagem, um dos componentes do ciberespaço, estão apoiadas pela interconexão, podendo ser um excelente meio de socialização que vêm potencializar a relação entre os humanos, onde as pessoas podem trocar mensagens, informações, sentidos e significados.

As comunidades virtuais são um novo meio de comunicação e de compartilhamento de informações, onde os participantes podem expor suas idéias e opiniões, mas ao mesmo tempo sem tirar a responsabilidade que cada componente deve ter. Sendo assim, é possível também a exposição da opinião pública, tornando-as ambientes democráticos e abertos.

Para tanto, são inúmeras as ferramentas que dão sustentação às comunidades virtuais de aprendizagem, como os fóruns de discussão, onde os participantes podem debater e trocar informações entre si, havendo uma reciprocidade de todos para todos. Também são exemplos: MSN messenger, ICQ, chat, skype, wiki, dentre tantas outras.

Portanto, essas ferramentas de comunicação são muito importantes e valiosas no processo de aprendizagem, como, por exemplo, na autoria colaborativa, uma vez que servem de suporte a esses, possibilitando a interação de seus usuários, bem como o registro e a vivência de processos de reflexão, troca e discussão acerca do objetivo comum.

\section{Autoria Colaborativa}

Foi visto que os ambientes virtuais de aprendizagem podem potencializar a inteligência coletiva e esse processo se desenvolve através da autoria colaborativa. A autoria colaborativa é uma modalidade de criação coletiva, portanto, elemento essencial para o processo de aprendizagem.

Os ambientes de autoria colaborativa devem oferecer aos autores a possibilidade de criar, por exemplo, textos, tanto de forma assíncrona, quanto síncrona, vivenciando uma experiência de multiplicidade de saberes. 
Outro ponto interessante é registrar os processos de autoria desenvolvidos, pois a cada leitura feita, uma nova reflexão surge e devido essa nova reflexão, são necessárias algumas mudanças na autoria. Com isso, tal mudança fica registrada como depoimento da atividade reflexiva.

\begin{abstract}
Pode-se pensar que estes pontos de deriva constituem possibilidade de produção de sentidos, configurando vetores que fazem emergir a poética da criação, na assunção de posições de autoria comprometidas com a potencialização, ao mesmo tempo de relações de reciprocidade e de condições favoráveis à autonomia (mesmo que relativa) de pensamento e de tomada de decisão, pela própria vivência desses processos na armação das tramas narrativas. (AXT et al 2006).
\end{abstract}

Assim, revendo alguns pontos da autoria colaborativa, observa-se que baseado na apropriação criativa, no desenvolvimento de uma forma de trabalho coletivo e compartilhado, estamos caminhando para uma cultura aberta e flexível, fundamental na ampliação do conceito de inclusão digital.

\title{
6. Inclusão Digital
}

Pôde-se verificar que a autoria colaborativa, juntamente com iniciativas de inclusão digital, tem um papel muito importante no processo de aprendizagem, uma vez que esta modalidade de inclusão, dentre outros objetivos, visa formar cidadãos capazes de tomar decisões e de compartilhá-las com outras pessoas, em uma dinâmica de exercício da autoria e da co-autoria.

Verificando esses fatos, inclusão digital pode ser definida como:

\begin{abstract}
Um processo dinâmico e provisório que se renova e aprimora na ação e na interação dos nós, sobre e na rede de sentidos e suas interconexões. Para isso, é necessária a apropriação crítico-reflexiva dos fenômenos sociotécnicos numa perspectiva de contextualização sociocultural, bem como o desenvolvimento e a manutenção das habilidades necessárias à interação com e através deles. (TEIXEIRA 2005, p. 25).
\end{abstract}

Para que esse processo ocorra, deve haver, inicialmente, uma democratização do acesso acompanhada da alfabetização digital e da possibilidade da pessoa se atualizar, com vistas ao desenvolvimento da fluência tecno-contextual.

Algumas ações que colaboram com iniciativas de inclusão digital são: considerar os fenômenos da cibercultura, criar cultura e competências para ação no ciberespaço, oferecer condições sócio-culturais, econômicas e políticas, sem afastá-las de sua realidade, sendo um complemento ao que já existe e sem romper com velhas práticas.

Assim, os objetivos da inclusão digital não deve ser formar técnicos, mas sim cidadãos responsáveis, que reconheçam suas potencialidades e responsabilidades, se apropriando de forma criativa e diferenciada das tecnologias de rede, libertando o ser humano de uma posição passiva. 
Com isso, podemos resgatar algumas características, próprias da sociedade contemporânea e que são pré-requisitos, fundamentais, para a inclusão digital: ser nó de rede, rompendo com a lógica broadcast e assumindo uma postura diferenciada, como autoria, autonomia, pró-atividade, criatividade, reconhecimento e valorização de identidade, capacidade cooperativa e respeito às diferenças, caminhando para a construção de processos reticulares e horizontais, de ampliação e valorização da nossa cultura, sem perder nossa real identidade.

\section{Metodologia da Pesquisa}

Esse estudo teve como objetivo verificar a pertinência das reflexões teóricas apresentadas a partir da proposta de atividades de autoria colaborativa e da análise das manifestações dos sujeitos envolvidos no processo.

Para essa investigação foi realizado um estudo junto a alunos do primeiro ano no Centro de Ensino Médio, da Universidade de Passo Fundo, na disciplina de redação. A pesquisa foi dividida em duas etapas: a primeira consistiu no acompanhamento e observação do processo tradicional de escrita da redação, onde o professor propôs o assunto a ser abordado e os alunos, individualmente, redigiram seus textos; a segunda, por sua vez, se deu de forma colaborativa, suportada por um ambiente virtual de aprendizagem.

No primeiro caso, além de um questionário sobre os procedimentos que os alunos normalmente tomam ao redigir suas redações, foi observado como alunos e professores trabalharam em sala de aula no método tradicional, sendo que foram feitas anotações para posterior comparação com o processo de autoria colaborativa.

A próxima etapa da pesquisa foi a realização de uma experiência de autoria colaborativa, pelos mesmos alunos ${ }^{3}$, a partir de um ambiente que suportasse, além da redação dos textos, o estabelecimento de processos criativos e dialógicos.

Essa segunda modalidade, buscando apropriar-se da lógica das redes, contou com o auxílio computacional, fazendo uso do ambiente colaborativo cujo principal objetivo foi suportar o processo de autoria colaborativa analisado posteriormente.

Para análise do processo, foram observados quais aspectos contemplaram, por exemplo, elementos da lógica das redes e do conceito de inclusão digital bem como de autoria colaborativa, além do comprometimento e da colaboração entre os participantes.

Deve-se observar que o objetivo principal da experiência não é avaliar nem alunos, nem professor, mas sim, contrapor o processo de aprendizagem tradicional com o de autoria colaborativa suportada pelas tecnologias de rede, a fim de verificar como esses contribuem para a formação escolar dos indivíduos.

Com a aplicação de um questionário e acompanhamento do processo de autoria colaborativa suportada por um ambiente virtual de aprendizagem, realizou-se uma contraposição dos dois modelos de autoria e ampliaram-se as reflexões acerca das questões detectadas anteriormente.

\footnotetext{
${ }^{3}$ Optou-se por escolher os mesmos alunos por estes serem do ensino médio da UPF, uma escola particular e que conta com estudantes de classe social alta e, portanto, possuem acesso às tecnologias de rede, se tornando a amostra ideal para o presente trabalho, onde provavelmente, todos já tenham tido algum contato com as tecnologias de rede, dentre outros aspectos.

V. 4 № 2, Dezembro, 2006
} 


\section{Análise do Processo de Autoria Tradicional}

Após o acompanhamento do processo de autoria tradicional e análise do questionário, que teve como principal objetivo criar um instrumento de coleta de dados para conhecer como se dá o processo de ensino tradicional para posteriormente compará-lo com o método de autoria colaborativa suportada pelas tecnologias de rede, constatou-se que a autoria tradicional está fortemente presente nas salas de aula, numa perspectiva reticular e verticalizada, antagônicas ao conceito de aprendizagem.

No entanto, acredita-se que, quando este se dá de forma colaborativa, pode trazer maiores benefícios, uma vez que a aprendizagem colaborativa pode abrir novos horizontes e com isso se tornar uma aliada na formação escolar dos mesmos, dadas as suas características como: criação e produção de textos, processos autorais, compartilhamento de sentidos, informações e significados, melhor convívio social, dentre outras, que contribuem para uma imaginação vasta e criadora.

Também é possível concluir que mesmo que o processo de aprendizado seja tradicional, há alguns elementos que nos remetem ao processo de inclusão digital e autoria colaborativa. No entanto, ainda há muito que mudar, principalmente na forma como o conteúdo é passado e na forma como este é recebido pelos alunos. Isso se comprovou no processo de autoria colaborativa suportada por um ambiente virtual de aprendizagem.

\section{Análise do Processo de Autoria Colaborativa}

Como na anterior, houve o acompanhamento do processo de autoria colaborativa, bem como a aplicação de um questionário, que além dos objetivos anteriores, teve o intuito de verificar como as tecnologias de rede podem sustentar e potencializar processos de autoria colaborativa suportada, por exemplo, por ambientes virtuais de aprendizagem.

Baseados nos conceitos apresentados e com o término da etapa de autoria tradicional, foi possível o desenvolvimento de um espaço de autoria colaborativa. Com a aplicação desse ambiente virtual de aprendizagem, ColaborE, e do questionário, além de outros elementos, acredita-se que a autoria colaborativa potencializa o aprendizado, no entanto, para que isso ocorra de forma efetiva, deve haver um comprometimento, tanto na atividade proposta quanto com os colegas.

No entanto, com a amostra de alunos que se trabalhou, verificou-se que apesar destes terem sido bastante dinâmicos e participativos no encontro presencial e destes terem acesso às tecnologias de rede, isso não significa que eles consigam ter uma atitude de nó ativo e se comprometer com processos colaborativos, reforçando dessa maneira, a teoria, onde foi visto que inclusão digital não é apenas acesso às tecnologias, mas sim, inclusão digital é comprometimento e auto-inclusão na atividade proposta.

Além disso, é importante colocar que em alguns grupos de alunos houve um maior comprometimento entre si, onde estes trabalharam de forma colaborativa, se apropriando das tecnologias de rede.

\section{Considerações Finais}

Após o término deste trabalho, algumas considerações podem ser realizadas, como: houve um grande enriquecimento intelectual, que se deve às leituras realizadas e ao 
estudo de caso, onde estes propiciaram um melhor entendimento do processo de aprendizagem e da sociedade contemporânea.

Além disso, não basta ter acesso à tecnologia, deve haver também uma autoinclusão, nos remetendo a resgatar um dos pontos chaves do presente trabalho: autoria colaborativa e inclusão digital, onde podemos dizer que a autoria colaborativa, juntamente com iniciativas de inclusão digital, tem um papel muito importante no processo de aprendizagem, uma vez que a inclusão digital tem como objetivo, dentre outros, formar cidadãos capazes de tomar decisões e de compartilhá-las com outras pessoas, em uma dinâmica de exercício da cidadania.

Com isso, observou-se que são grandes as diferenças entre os dois modelos propostos, o de autoria tradicional e o de autoria colaborativa, uma vez que no primeiro modelo há ainda uma separação entre professor, que sabe, e aluno, que aprende. Já a autoria colaborativa, se mostrou aberta e flexível, sem a forte presença do ensinoaprendizagem como processos distintos.

No entanto, há também uma semelhança entre os modelos: se não houver o comprometimento e a auto-inclusão na atividade proposta, nenhum dos modelos pode ser potencializado, independente da presença de tecnologias, ou seja, se não for nó de rede em constante movimento comunicacional e não houver mudança de postura e o rompimento com a lógica broadcast, o aprendizado não será efetivo.

\section{Referências Bibliográficas}

AXT, M. et al. (2006) Era uma vez...co-autoria em narrativas coletivas intersecionadas por tecnologias digitais. Disponível em: $<$ http://www.observatorio.unesco.unb.br/comum/view=verarquivo\&cod=363>.

Acessado em: 14 mar. 2006.

CAPRA, F. As conexões ocultas: Ciência para uma vida sustentável. São Paulo: Cultrix, 2002.

LEMOS, A. A inteligência coletiva: por uma antropologia do ciberespaço. 4.ed. São Paulo: Loyola, 2003.

. (2003) Cibercultura: alguns pontos para compreender a nossa época. Disponível em: <http://www.facom.ufba.br/ciberpesquisa/andrelemos/cibercultura.pdf>. Acesso em: 18 mar. 2006.

. (2004a) Cibercidades. Um modelo de inteligência coletiva. Disponível em: <http://www.facom.ufba.br/ciberpesquisa/andrelemos/modelo.pdf >. Acesso em: 14 mar. 2006.

(2004b) Cibercultura, Cultura e Identidade. Em direção a uma “Cultura Copyleft"?. Disponível em:

$<$ http://www.facom.ufba.br/ciberpesquisa/andrelemos/copyleft.pdf $>$. Acesso em: 14 mar. 2006.

LÉVY, P. As tecnologias da inteligência: o futuro do pensamento da era da informática. Rio de Janeiro: 34, 1993.

. (2003) A inteligência coletiva: por uma antropologia do ciberespaço, 4.ed. São Paulo, Loyola.

SILVA, M. Sala de aula interativa. Rio de Janeiro: Quartet, 2000. 
RAMAL, A. C. Educação na cibercultura: hipertextualidade, leitura, escrita e aprendizagem. Porto Alegre: Artmed, 2002.

TEIXEIRA, A. C. Formação docente e inclusão digital: a análise do processo de emersão tecnológica de professores, 2005. Tese de doutorado.

SANTOS, Milton. A natureza do espaço: técnica e tempo, razão e emoção. São Paulo: Universidade de São Paulo, 2002.

WIKIPEDIA. Ciberespaço. Disponível em:

<http://pt.wikipedia.org/wiki/Ciberespa\%C3\%A7o>. Acesso em:10 abr. 2006. 